\section{The European Summit on Hospital Pharmacy}

\author{
Roberto Frontini ${ }^{1,2}$
}

It has often been said that the best way to predict the future is to create it. It was with this thought in mind that the Board of the European Association of Hospital Pharmacists (EAHP) realised the need for the hospital pharmacy profession in Europe to more precisely chart and define the future practice goals and roles that it should achieve in all European countries. This was the essence of the European Summit on Hospital Pharmacy, and the 44 European Statements of Hospital Pharmacy that it created. The statements now form the primary foundation for delivering EAHP's practice development mission, and a charter for improving patient care in hospitals that every EAHP member country can make use of.

This special edition of the European Journal of Hospital Pharmacy explains more about the purpose and intent of the statements and the reason they matter for practice improvement in all European health systems.

The project took as its basis the excellent work of the International Pharmaceutical Federation (FIP)'s hospital pharmacy section in creating the 'Basel Statements', a unique and international expression of what the hospital pharmacy profession should be. Six years on from this endeavour however, it was important to ensure that the new European Statements of Hospital Pharmacy reflected both changes in practice aspiration in that time, and the uniqueness of Europe's health landscape. The initial work to achieve such a review was led by Aida Batista through a Working Group of hospital pharmacists from a broad spread of European countries, and her article sums up the results of that first item of activity.

We were delighted that from the very launch of the initiative we were able to

\footnotetext{
${ }^{1}$ European Association of Hospital Pharmacists, Brussels, Belgium; ${ }^{2}$ Universitätsklinikum Leipzig, Leipzig, Germany
}

Correspondence to Dr Roberto Frontini, European Association of Hospital Pharmacists, Rue Abbé Cuypers. 3, Brussels B-1040, Belgium; president@eahp.eu benefit from the involvement, input, knowledge and experience of Lee Vermuelen and many others from the FIP hospital pharmacy section. This provided a real connection between the international Basel Statements and the new European Statements of Hospital Pharmacy. With the Basel Statements themselves scheduled for review, the close working between EAHP and FIP on raising practice standards will be as important as ever. Lee Vermuelen provides an article for this supplement, telling more about the Basel Statements and their relationship to the European statements.

Following the initial review of the Basel Statements, Neal Maskrey and Jonathan Underhill outline the painstaking consultation process undertaken ahead of, and at, the Summit. An adapted Delphi methodology was employed to ensure the full kaleidoscope of opinion and aspirationfrom all corners of Europe, and from patient, to health professional, to hospital pharmacist - could be reflected in the final outcome. The effort was certainly worth it, with the Statements now representing what we believe to be an unprecedented level of consensus, not just between the hospital pharmacy profession, but with its primary stakeholders too. My own article provides an analysis of the Summit voting, while EAHP officers Richard Price and David Preece provide post-Summit considerations of the experience and feedback received from patient organisations, healthcare professional organisations and EAHP members on their participation in the Statement forming process.

Other articles from fellow contributors explain some of the other important associated activity of the Summit that focused on how to ensure the European Statements of Hospital Pharmacy move promptly from aspiration to reality. This includes an exposition by Professor Dr Cees Neef about the new Good Practice Initiatives index being catalogued by EAHP (what we call a 'stepwise approach' to practice development), Dr David Cousins' exploration of metrics used in hospital pharmacy around Europe, "what gets measured gets done!", Petr Horák's explanations on the future of EAHP-Survey, and Professor David Gerrett's reflections on the implementation challenges hospital pharmacists face across Europe. There will be much more to be shared in future editions of the Journal on this topic as the modus operandi of EAHP's practice development activity moves firmly towards implementation of the Statements.

From the outset, our desire was to create goals for the hospital pharmacy profession in Europe that were both challenging and ambitious, but also achievable and realistic. I believe, through the contributions of so many EAHP members, stakeholder organisations and Summit project team members, that achievement is reflected in the end result: the European Statements of Hospital Pharmacy.

I now cordially invite you to read and reflect on the Statements, and begin your own considerations about the extent to which they are being achieved in your hospital. Think too about the activity that may be required in your country to ensure each and every one is, in time, met. Excellence, after all, can be said to be the gradual result of always striving to do better.

EAHP and its members will continue to work on developing a variety of tools to assist the use of the Statements, but otherwise, the country-by-country gap analysis may already begin. In this sense, every hospital pharmacist in Europe should consider themselves a part of the Statements project, and we look forward to further work with you...

Photographs from the European Summit on Hospital Pharmacy 2014 are available on the EAHP website at http://www.eahp.eu/press-room/multimedia/european-summit-hospitalpharmacy-2014.

Competing interests None.

Provenance and peer review Commissioned; internally peer reviewed.

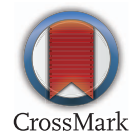

To cite Frontini R. Eur J Hosp Pharm 2014;21:255.

Eur J Hosp Pharm 2014;21:255.

doi:10.1136/ejhpharm-2014-000517 